\title{
Effect of adrenalectomy on remission of subclinical left ventricular dysfunction in patients with pheochromocytoma: a speckle-tracking echocardiography study
}

\author{
Jan Kvasnička1, Ondřej Petrák1 ${ }^{1}$, Tomáš Zelinka ${ }^{1}$, Judita Klímová1 ${ }^{1}$ Barbora Kološová1, Květoslav Novák², \\ David Michalský ${ }^{3}$, Jiří Widimský Jr ${ }^{1}$ and Robert Holaj1 \\ 13rd Department of Medicine, General University Hospital and 1st Faculty of Medicine, Charles University in Prague, Praha, Czech Republic \\ ${ }^{2}$ Department of Urology, General University Hospital and 1st Faculty of Medicine, Charles University in Prague, Praha, Czech Republic \\ ${ }^{3}$ 1st Department of Surgery, General University Hospital and 1st Faculty of Medicine, Charles University in Prague, Praha, Czech Republic \\ Correspondence should be addressed to R Holaj: robert.holaj@vfn.cz
}

\begin{abstract}
Background: Pheochromocytomas (PHEO) are tumours with the ability to produce, metabolize and secrete catecholamines. Catecholamines overproduction leads to the decrease of longitudinal function of the left ventricle (LV) measured by speckle-tracking echocardiography. Patients with PHEO have a lower magnitude of global longitudinal strain (GLS) than patients with essential hypertension. GLS normalization is expected after resolution of catecholamine overproduction.

Methods: Twenty-four patients (14 females and 10 males) with a recent diagnosis of PHEO have been examined before and 1 year after adrenalectomy. An echocardiographic examination including speckle-tracking analysis with the evaluation of GLS and regional longitudinal strain (LS) in defined groups of LV segments (basal, mid-ventricular and apical) was performed.

Results: One year after adrenalectomy, the magnitude of GLS increased $(-14.3 \pm 1.8$ to $-17.7 \pm 1.6 \% ; P<0.001)$. When evaluating the regional $L S$, the most significant increase in the differences was evident in the apical segment compared to mid-ventricular and basal segments of LV $(-5.4 \pm 5.0$ vs $-1.9 \pm 2.7$ vs $-1.6 \pm 3.8 ; P<0.01)$. Conclusions: In patients with PHEO, adrenalectomy leads to an improvement of subclinical LV dysfunction represented by the increasing magnitude of GLS, which is the most noticeable in apical segments of LV.
\end{abstract}

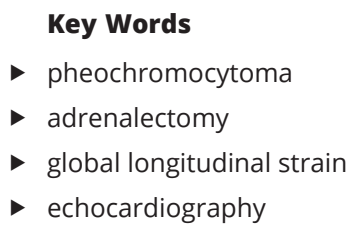

Endocrine Connections (2021) 10, 1538-1549

\section{Introduction}

Pheochromocytomas (PHEO) and functional paragangliomas (PGLs) are rare and mostly non-metastatic tumours originating from chromaffin tissue either from the adrenal medulla (PHEO) or from the vegetative nervous system-associated chromaffin tissue (PGLs) (1). Both types of tumours are collectively referred to as PPGLs. The prevalence of PHEO and PGLs in non-selected population of patients with arterial hypertension is between 0.2 and
$0.6 \%(2,3)$. The prevalence of PHEO is higher than the prevalence of PGLs, when $80-85 \%$ of PPGL are PHEO, whereas $15-20 \%$ are PGLs (4). The incidence has been rising due to the general ageing of the population and smaller tumour sizes at diagnosis in recent years (5).

PPGL can produce, metabolize and secrete catecholamines, which are responsible for a large variety of signs because of their hemodynamic and metabolic

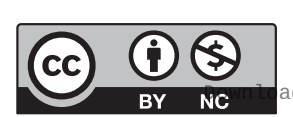


effects. In particular, these signs are paroxysmal, such as headache, perspiration, palpitations and arterial hypertension $(4,6)$. Patients with PPGL may have more serious cardiovascular complications (even life-threatening ones, such as arrhythmias, myocardial infarction or heart failure), compared to patients with essential hypertension (EH) (7). Adrenalectomy also leads to an improvement of left ventricle (LV) mass in patients with PHEO (8). The aforementioned heart failure may be caused by the PPGLassociated catecholamine cardiomyopathy. The most severe form can be the clinical manifestation of Takotsubo syndrome (TTS) in which PPGL acts as its triggering factor. Most older diagnostic criteria for TTS preclude a diagnosis of PPGL, but the latest International Takotsubo Diagnostic Criteria (InterTAK) already directly list PPGL as a specific cause of TTS (9). These clinical conditions are usually transient and resolve after the removal of the catecholamine-producing tumour $(10,11)$.

An echocardiographic technique - 2D global longitudinal strain (GLS) derived from 2D speckle-tracking echocardiography - seems to be an already well-established and in certain situations more appropriate method for evaluating LV function, including myocardial motion and longitudinal deformation, than commonly used LV ejection fraction (EF) (12). GLS can also detect LV systolic impairment early on in the preclinical stage, while EF still remains in a normal range, and the analysis of regional values of longitudinal strain (LS) also allows the assessment of individual segments of the LV (13). This advantage of GLS over EF in patients with PHEO has already been confirmed by our previous study (14). Further studies have confirmed the improvement of GLS after surgical removal of PHEO $(15,16)$.

As mentioned above, catecholamine-induced myocardial dysfunction caused by PPGL is often compared and in some cases difficult to distinguish from TTS $(11,17)$. TTS is most often manifested by dysfunction of the apical segments of LV, but localization can occur anywhere in LV, as it has also been described for PPGL-triggered TTS (18). Therefore, we have designed this prospective study to confirm the positive effect of surgical removal of PPGLs on individual echocardiographic parameters and especially to evaluate the regional function of individual segments of the LV.

\section{Methods}

Subjects

The patients were recruited from a cohort of almost 1400 patients investigated because of resistant hypertension, paroxysmal symptoms suspected of PPGL or adrenal tumours at our tertiary hospital-based Centre for Hypertension at the Third Department of Medicine, General University Hospital and First Faculty of Medicine, Charles University in Prague between November 2015 and November 2019. Each participant provided their written informed consent, and the study protocol was approved by the local Ethics Committee which took place during the grant approval (on 21 May 2015, code 20/15). The study was conducted in accordance with the Declaration of Helsinki.

The diagnosis of PPGL was newly confirmed in 62 patients during the aforementioned period, which represents circa a $4 \%$ rate in this preselected population. The diagnosis of PPGL was based on elevated plasma metanephrines and normetanephrines above the upper reference limit, and a positive finding of adrenal tumour on CT or MRI and/or a positive study with PET/CT with fluorodopa/fluorodeoxyglucose or ${ }^{123}$ I-metaiodobenzylguanidine scintigraphy. After examination, all subjects underwent surgical removal of the tumour and the diagnosis was confirmed histopathologically. The noradrenergic (NA) biochemical phenotype was defined as a predominant increase in normetanephrine only, accompanied by either normal plasma concentrations of metanephrine or by an increase of $<5 \%$ in metanephrine, relative to the sum of increments for both metabolites. Conversely, the adrenergic (A) biochemical phenotype was defined by an increase of plasma metanephrine above the upper reference limits and associated increments, relative to the combined increments of both metabolites, of $>5 \%$ in metanephrine $(19,20)$.

Thirty-eight patients were excluded from this group due to various circumstances. The flow chart for enrolling patients in the study is shown in Fig. 1.

The subjects were considered hypertensive when their office BP was $\geq 140 / 90 \mathrm{mmHg}$ or $\geq 130 / 80 \mathrm{mmHg}$; an average of three measurements was calculated based on measurements performed on three individual days or $\geq 130 / 80 \mathrm{mmHg}$ measured with 24-h ambulatory blood pressure monitoring (21). Diabetes mellitus was defined as medication with oral antidiabetic drugs or repeated fasting glucose levels of $\geq 7.0 \mathrm{mmol} / \mathrm{L}$ (22). All subjects with dyslipidemia ( $\mathrm{LDL} \geq 3.0 \mathrm{mmol} / \mathrm{L}$ ) were on a diet and received lipid-lowering therapy (23).

All patients were initially examined during a short 3-day hospitalization on therapy that did not affect the renin-angiotensin-aldosterone system. Therefore, chronic antihypertensive therapy was discontinued at least 2 weeks before admission, and patients were switched to the treatment with $\alpha$-blockers and/or slow-release verapamil. 


\section{Diagnosis of PPGL (62)}

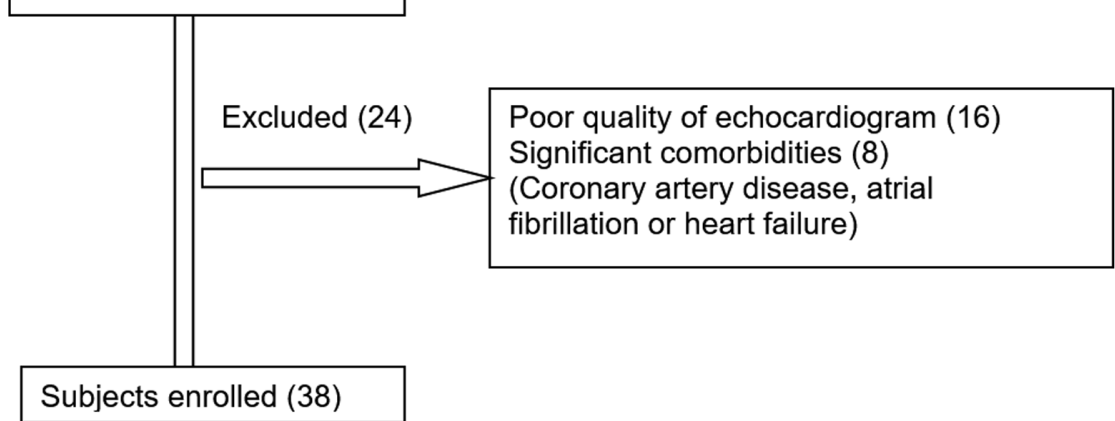

Subjects enrolled (38)

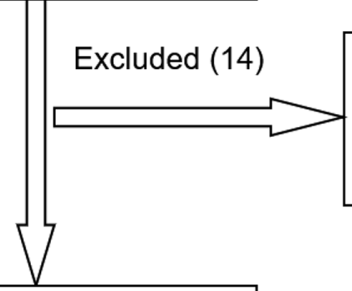

Bilateral adrenalectomy (1)

Incomplete resection (1)

Multiple or metastatic paraganglioma (5)

Lost to follow-up (7)

Subjects analyzed (24)

A diagnosis of PPGL was followed by standard pharmacological treatment with $\alpha$-blockers followed by $\beta$-blockers until surgical treatment. Another 2-day hospitalization, including control echocardiography examination, was performed 12 months after the first examination.

\section{BP measurement}

Office blood pressure was measured using an oscillometric device (Omron M6, Shimogyo-ku, Kyoto, Japan). The measurement was made in a quiet room with the patient's arm positioned at the heart level and on chronic antihypertensive treatment during the first ambulatory visit, prior to switching to the treatment with $\alpha$-blockers and/or slow-release verapamil. Blood pressure was measured three times in a sitting position after $5 \mathrm{~min}$ of rest. The final value of causal systolic and diastolic blood pressure was calculated as the average from the second and third measurements. The patient's 24 -h blood pressure was measured during their stay in the hospital using an oscillometric device (SpaceLabs 90207, SpaceLabs Medical, Redmond, WA, USA) already on the replaced medication. Monitors were programmed to measure BP at 20-min intervals from 06:00 to 22:00 $\mathrm{h}$ and at 30-min intervals from 22:00 to 06:00 h. Fixed-clock time periods, rather than actual in-bed and out-of-bed periods, were statistically analysed to ensure similar day- and night-time periods for comparison between individuals. Moreover, patients were investigated during a short hospitalization with the same

\section{Figure 1}

Study flowchart in patients with pheochromocytoma or functional paraganglioma (PPGL). daily hospital regime where the day and night periods ranged from 06:00 to 22:00 $\mathrm{h}$ and from 22:00 to $06: 00 \mathrm{~h}$, respectively. At a follow-up 1 year after the adrenalectomy, office blood pressure was measured in the same manner again during the outpatient visit and 24-h blood pressure was measured during a 2-day rehospitalization on chronic treatment.

\section{Laboratory}

Plasma catecholamines were analysed by HPLC with a fluorometric detector (HPLC/FLD 1100S, Agilent Technologies Inc.). The system was calibrated with a catecholamine standard using the ClinRep test kit (Recipe Chemicals and Instruments $\mathrm{GmbH}$, Munich, Germany). Plasma-fractioned metanephrine (metanephrine and normetanephrine) was quantified by liquid chromatography with electrochemical detection (HPLC/ED 1100, Agilent Technologies Inc.) in the Laboratory for Endocrinology and Metabolism at the Third Department of Medicine, General University Hospital and First Faculty of Medicine, Charles University in Prague (24). Blood biochemistry, including sodium, potassium, urea, creatinine, total cholesterol, LDL, HDL, triglycerides and plasma glucose, was analysed using a multi-analyser (Modular SWA; Roche Diagnostics) in the Institute of Medical Biochemistry and Laboratory Diagnostics of the General University Hospital and First Faculty of Medicine, Charles University in Prague with international accreditation. Creatinine clearance was determined during $24 \mathrm{~h}$ of urine collection. 


\section{Echocardiography}

2D Doppler and 2D speckle-tracking echocardiography was performed according to the recommendations of the American Society of Echocardiography and the European Association of Cardiovascular Imaging (25) on Vivid E9 ultrasound system (GE Healthcare). This approach was described in detail elsewhere (14).

The 2D speckle-tracking analysis was performed by automated detection of the endocardial border after manually defining the basal and apical points of the LV myocardium. The 17-segment ventricular model was obtained from 3 projections at end-expiration: apical 4-chamber view, 2-chamber view and apical long-axis view. Then GLS was computed as the mean of peak LS values from each of these segments according to the consensus of the American Society of Echocardiography and the European Association of Echocardiography endorsed by the Japanese Society of Echocardiography (26). As recommended, patients were excluded if tracking was insufficient in more than one segment due to suboptimal visualization or artefacts. The mid-wall GLS and peak LS in individual segments were evaluated. Individual segments, like basal, mid-ventricular and apical, were unified for simplification. The normal range of GLS using GE Healthcare system was from -18.0 to $-21.5 \% \pm 3.7 \%$ (27).

\section{Reproducibility sub-study}

Echocardiographic images were recorded by two cardiologists with over 20 years of echocardiography experience ( $\mathrm{R} \mathrm{H}$ and $\mathrm{O} \mathrm{P}$ ) during the hospitalization of patients in our ward.

Furthermore, these two cardiologists performed offline identical duplicate measurement and evaluation of the basic echocardiographic parameters using the EchoPAC working station (v.113, Advanced Analysis Technologies; GE Healthcare) within 3 weeks. Reproducibility was quantified by the assessment of coefficients of variation within the pairs of measurements for individual patients, identically as in our previous work (8). These were subsequently averaged in order to obtain the mean coefficient of variation with a corresponding S.D. Reproducibility of individual parameters was as follows: $4.5 \pm 3.6 \%$ for interventricular septum thickness (IVS), $2.0 \pm 2.0 \%$ for LV end-diastolic diameter (LVED), $2.4 \pm 1.9 \%$ for $\mathrm{LV}$ end-systolic diameter (LVES), $4.4 \pm 3.0 \%$ for posterior wall thickness (PWT) and $5.5 \pm 4.8 \%$ for left atrium diameter (LA).

The 2D speckle-tracking analysis was performed again offline using the EchoPAC working station by one cardiologist (J K) with over 7 years of experience using this method. Reproducibility sub-study was not performed as GLS should be an objective method with little dependence on inter-observer variability (28).

\section{Statistical analysis}

The statistical analysis was performed by STATISTICA software version 12.5 (Statsoft, Tulsa, Oklahoma, USA). Normally distributed data were described by mean \pm S.D. $P$-values of $<0.05$ were considered statistically significant. Continuous variables with clearly nonnormal distributions (Shapiro-Wilks W-test) were described as medians (interquartile range). The paired measurements (PHEO before adrenalectomy and after adrenalectomy) were compared using either $t$-test for dependent samples or Wilcoxon matched-pairs test, as appropriate. The difference between two treatment groups was analysed by $t$-test for independent samples. Multiple-group comparisons were performed by one-way ANOVA, followed by the Scheffe's multiple range test. Changes from the baseline of regional LS measurement were assessed by two-way ANOVA. Pearson's correlation analysis was used to assess the relationship between the GLS and other clinical parameters as well as the relationship between their treatment-induced changes. Spearman's correlation was used for non-normally distributed indices.

\section{Results}

\section{Clinical data}

The final group included 24 patients with a biochemically and histologically confirmed diagnosis of PHEO (18 subjects with adrenergic phenotype and 6 subjects with noradrenergic phenotype), aged from 29 to 78 years (14 females and 10 males). Clinical characteristics of the final group of patients are shown in Table 1 . The follow-up was 12 months. After the adrenalectomy, an increase in the patients' body weight was observed and therefore their BMI significantly increased $(P<0.05)$. Sixteen patients $(67 \%)$ became normotensives, and their antihypertensive therapy was discontinued, whereas eight patients still required antihypertensive therapy although at reduced doses and with a lower number of agents compared to baseline (Table 2). A significant reduction in the number of antihypertensive drugs was achieved with $\alpha$-blockers, $\beta$-blockers and calcium channel blockers $(P<0.01)$ (Table 3$)$. 
Table 1 Clinical characteristics of patients at the beginning of the study.

Clinical characteristics
Localization of tumours
Phenotype
Hereditary forms
Severity of hypertension

Myocardial involvement

Paroxysmal symptoms (as a reason for clinical examination)

\begin{tabular}{l} 
Right side \\
Left side \\
Bilateral \\
Extra-adrenal \\
Elevated plasma adrenaline and noradrenaline \\
(or plasma metanephrine and normetanephrine) \\
Elevated only plasma noradrenaline (or only plasma \\
normetanephrine) \\
Neurofibromatosis type 1 \\
Transmembrane protein 127 gene \\
Normotension \\
Mild grade \\
Moderate grade \\
Severe grade \\
Myocardial infarction \\
Takotsubo-like cardiomyopathy \\
Hypertension crisis \\
Sweating \\
Headache \\
Palpitation \\
Hypertension \\
Vertigo \\
Intestinal symptoms \\
Vomiting \\
Colour changes \\
Chest pain \\
No symptoms \\
\hline
\end{tabular}

\begin{tabular}{|c|c|}
\hline$n$ & (\%) \\
\hline 13 & 54 \\
\hline 11 & 46 \\
\hline 0 & 0 \\
\hline 0 & 0 \\
\hline 18 & 75 \\
\hline 6 & 25 \\
\hline 1 & 4 \\
\hline 1 & 4 \\
\hline 6 & 25 \\
\hline 10 & 42 \\
\hline 5 & 21 \\
\hline 3 & 12 \\
\hline 1 & 4 \\
\hline 1 & 4 \\
\hline 1 & 4 \\
\hline 11 & 46 \\
\hline 10 & 42 \\
\hline 7 & 30 \\
\hline 6 & 25 \\
\hline 5 & 21 \\
\hline 5 & 21 \\
\hline 3 & 12 \\
\hline 1 & 4 \\
\hline 1 & 4 \\
\hline 7 & 30 \\
\hline
\end{tabular}

Moreover, 24-h systolic and diastolic BP significantly decreased $(P<0.005$ and $P<0.05$, respectively) although the office blood pressure values insignificantly increased. Both office and 24 -h heart rate $(P<0.05)$ significantly decreased (Table 2).

\section{Laboratory data}

As expected, after the tumour removal, plasma-fractioned metanephrines also normalized $(P<0.001)$ (Table 4$)$.
Six patients with PHEO met the criteria for a diagnosis of diabetes, and after the tumour removal, diabetes disappeared in three patients. The overall improvement in glucose metabolism resulted in the discontinuation of insulin by all patients who had been on such treatment, and the three remaining patients with diabetes mellitus were only continued on oral hypoglycaemic agents. Moreover, the fasting blood glucose showed a significant decrease $(P<0.001)$, while lipid levels and renal function did not change (Table 5).

Table 2 Clinical characteristic of the study population. Variables are shown as means \pm S.D.

\begin{tabular}{l}
\hline Age (years) \\
Height $(\mathrm{cm})$ \\
Weight $(\mathrm{kg})$ \\
Body mass index $\left(\mathrm{kg} / \mathrm{m}^{2}\right)$ \\
Systolic office BP $(\mathrm{mmHg})$ \\
Diastolic office BP $(\mathrm{mmHg})$ \\
Heart rate office (BPM) \\
24-h ABPM systolic BP $(\mathrm{mmHg})$ \\
24-h ABPM diastolic BP $(\mathrm{mmHg})$ \\
24-h ABPM heart rate (BPM) \\
Number of used antihypertensive drugs
\end{tabular}

\begin{tabular}{c} 
Before adrenalectomy $(n=24)$ \\
\hline $54 \pm 12$ \\
$169 \pm 9$ \\
$76 \pm 15$ \\
$26 \pm 4$ \\
$131 \pm 10$ \\
$81 \pm 9$ \\
$79 \pm 10$ \\
$131 \pm 11$ \\
$78 \pm 7$ \\
$77 \pm 8$ \\
$1.9 \pm 1.2$
\end{tabular}

\begin{tabular}{c} 
After adrenalectomy $(n=24)$ \\
$55 \pm 12$ \\
$169 \pm 9$ \\
$79 \pm 16$ \\
$27 \pm 4$ \\
$134 \pm 13$ \\
$83 \pm 7$ \\
$74 \pm 5$ \\
$122 \pm 8$ \\
$74 \pm 5$ \\
$71 \pm 6$ \\
$0.6 \pm 0.8$ \\
\hline
\end{tabular}

\begin{tabular}{c}
\hline P-value \\
\hline$<0.001$ \\
NS \\
$<0.05$ \\
$<0.05$ \\
NS \\
NS \\
$<0.05$ \\
$<0.005$ \\
$<0.05$ \\
$<0.05$ \\
$<0.001$
\end{tabular}

ABPM, ambulatory blood pressure monitoring; BP, blood pressure; NS, non-significant; PHEO, pheochromocytoma.

$\begin{array}{lr}\text { https://ec.bioscientifica.com } & \text { (c) } 2021 \text { The authors } \\ \text { https://doi.org/10.1530/EC-21-0462 } & \text { Published by Bioscientifica Ltd }\end{array}$

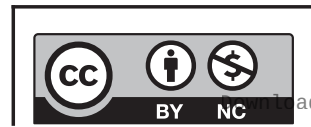

This work is licensed under a Creative Commons Attribution-NonCommercial 4.0 International License. ded from Bioscientifica.com at 04/26/2023 10:41:43AM via free access 
Table 3 Use of antihypertensive, antidiabetic and lipid-lowering drugs in study population. Values are represented as absolute numbers (percentages).

Diuretics $(n(\%))$
$\beta$-blockers $(n(\%))$
Calcium channel blockers $(n(\%))$
Angiotensin-converting enzyme inhibitors $(n(\%))$
Angiotensin receptor blockers $(n(\%))$
$\alpha$-blockers $(n(\%))$
Central agonists $(n(\%))$
Aldosterone antagonists $(n(\%))$
Statins $(n(\%))$
Insulin $(n(\%))$
Oral antidiabetic drugs $(n(\%))$

\begin{tabular}{c} 
Before adrenalectomy $(n=24)$ \\
\hline $6(25)$ \\
$11(46)$ \\
$7(29)$ \\
$7(29)$ \\
$4(17)$ \\
$8(33)$ \\
$2(8)$ \\
$1(4)$ \\
$8(33)$ \\
$3(13)$ \\
$4(17)$ \\
\hline
\end{tabular}

\begin{tabular}{c}
\hline After adrenalectomy $(n=24)$ \\
\hline $3(13)$ \\
$3(13)$ \\
$0(0)$ \\
$5(21)$ \\
$1(4)$ \\
$0(0)$ \\
$0(0)$ \\
$0(0)$ \\
$8(33)$ \\
$0(0)$ \\
$3(13)$
\end{tabular}

\begin{tabular}{c}
\hline $\boldsymbol{P}$-value \\
\hline NS \\
$<0.005$ \\
$<0.005$ \\
NS \\
NS \\
$<0.005$ \\
NS \\
NS \\
NS \\
$<0.05$ \\
NS
\end{tabular}

NS, non-significant.

\section{Echocardiographic parameters}

One year after adrenalectomy, there was a significant decrease in IVS from $10.3 \pm 1.7 \mathrm{~mm}$ to $9.3 \pm 1.1 \mathrm{~mm}$ $(P<0.005)$ and PWT from $10.1 \pm 1.5 \mathrm{~mm}$ to $9.2 \pm 0.8 \mathrm{~mm}$ $(P<0.05)$. As the LVED and the LVES remained unchanged, the RWT decreased from $0.43 \pm 0.08$ to $0.39 \pm 0.05(P<0.05)$. These changes in diameters of the LV also affected its total mass. There was a significant decrease in both indexed left ventricular masses LVMi/BSA (left ventricular mass index to the body surface area) from $95.3 \pm 18.7 \mathrm{~g} / \mathrm{m}^{2}$ to $83.6 \pm 17.8$ $\mathrm{g} / \mathrm{m}^{2}(P<0.05)$ and LVMi (left ventricular mass index) from $43.2 \pm 10.6 \mathrm{~g} / \mathrm{m}^{2.7}$ to $37.9 \pm 9.7 \mathrm{~g} / \mathrm{m}^{2.7}(P<0.05)$. There was also a reduction in the LA 1 year after adrenalectomy from $37.6 \pm 5.0 \mathrm{~mm}$ to $35.2 \pm 3.9 \mathrm{~mm}(P<0.05)$. The above data are listed in Table 6 .

As we expected, the basic parameter of systolic function - LV EF remained unchanged after 1 year, as patients with PHEO already had normal values of LV EF before the adrenalectomy. The estimation of the LV filling pressures expressed as the $\mathrm{E} / \mathrm{e}^{\prime}$ ratio also remained unchanged.

When evaluating LV function using 2D speckletracking echocardiography, we observed a significant increase of GLS from $-14.3 \pm 1.8$ to $-17.7 \pm 1.6(P<0.001)$. This increase was evident in all groups of LV segments (basal, mid-ventricular and apical), when evaluating the regional LS (Table 7). Overall, the highest values of regional LS were reached in apical segments compared to midventricular and basal segments $(-20.7 \pm 3.2$ vs $-17.5 \pm 2.1$; $-16.2 \pm 2.1 ; P<0.01 ; P<0.001$ ), and subsequently, the most significant increase in the differences between the regional LS was also evident after adrenalectomy in apical segments compared to mid-ventricular and basal segments $(-5.4 \pm 5.0$ vs $-1.9 \pm 2.7 ;-1.6 \pm 3.8 ; P<0.05 ; P<0.01)$ (Fig. 2 and Table 8). Typical examples of an echocardiographic pattern with GLS 'bull's-eye' diagrams and values of regional LS, including deformation curves before and 1 year after adrenalectomy, are shown in Figs 3 and 4 .

\section{Discussion}

Our study confirmed previous results that normalization of catecholamine in patients with PHEO leads to a positive LV remodelling (8) and an improvement in the longitudinal LV function and deformation represented by GLS (15). Moreover, we primarily focused on the evaluation of regional LS in individual LV segments and the effect of adrenalectomy on their final function. In our study, we have shown that the most significant improvement in regional LS values occurs in the apical segments of LV.

Table 4 Endocrine laboratory data. Values are shown as medians (interquartile range).

\begin{tabular}{l} 
\\
\hline Plasma metanephrine (nmol/L) \\
Plasma normetanephrine (nmol/L) \\
Plasma adrenaline (nmol/L) \\
Plasma noradrenaline (nmol/L \\
Plasma dopamine (nmol/L)
\end{tabular}

\begin{tabular}{c}
\hline Before adrenalectomy $(n=24)$ \\
\hline $4.28(0.83-10.42)$ \\
$6.57(3.74-22.13)$ \\
$2.00(0.35-2.82)$ \\
$7.96(3.95-15.37)$ \\
$0.24(0.15-0.29)$ \\
\hline
\end{tabular}

$\begin{array}{r}\text { After } \\ \\ \\ \hline\end{array}$


Table 5 Laboratory data of the study population. Variables are shown as means \pm S.D.

\begin{tabular}{l}
\hline \\
\hline Creatinine $(\mu \mathrm{mol} / \mathrm{L})$ \\
Creatinine clearance $(\mathrm{mL} / \mathrm{min})$ \\
Total cholesterol $(\mathrm{mmol} / \mathrm{L})$ \\
$\mathrm{HDL}$ cholesterol $(\mathrm{mmol} / \mathrm{L})$ \\
$\mathrm{LDL}$ cholesterol $(\mathrm{mmol} / \mathrm{L})$ \\
Triglycerides $(\mathrm{mmol} / \mathrm{L})$ \\
Fasting plasma glucose $(\mathrm{mmol} / \mathrm{L})$
\end{tabular}

\begin{tabular}{c}
\hline Before adrenalectomy $(n=24)$ \\
\hline $71 \pm 16$ \\
$135 \pm 34$ \\
$4.4 \pm 0.6$ \\
$1.4 \pm 0.2$ \\
$2.6 \pm 0.7$ \\
$1.3 \pm 0.5$ \\
$6.1 \pm 1.0$
\end{tabular}

\begin{tabular}{c}
\hline After adrenalectomy $(n=24)$ \\
\hline $75 \pm 12$ \\
$119 \pm 26$ \\
$4.4 \pm 0.7$ \\
$1.4 \pm 0.4$ \\
$2.8 \pm 0.8$ \\
$1.3 \pm 0.5$ \\
$5.0 \pm 0.5$
\end{tabular}

\begin{tabular}{c}
\hline P-value \\
\hline NS \\
NS \\
NS \\
NS \\
NS \\
NS \\
$<0.001$
\end{tabular}

HDL, high-density lipoprotein; LDL, low-density lipoprotein; NS, non-significant.

Regional discrepancies between individual LV segments are already known in clinical practice. For example, hypertrophic cardiomyopathy (HCM) is characterized by an overall reduction in GLS, but a regional reduction in LS correlates with the HCM phenotype (29). In the case of cardiac amyloidosis, regional LS is reduced mainly in the basal and mid-ventricular segments of the LV and this pattern is called 'apical sparing' (30). Fabry's disease also shows a decrease in regional LS, especially in the basal posterior and lateral segments (31). In patients with PHEO, no typical echocardiographic patterns of regional LS have been described.

In the case of patients with PHEO, however, a pathophysiological resemblance to TTS is presented. PHEO is considered a specific cause of TTS and is listed as one of the InterTAK Diagnostic Criteria for the diagnosis of TTS (9). The exact pathophysiology of TTS remains unclear, but certainly, the main mechanism includes sympathetic

Table 6 Echocardiographic parameters and Doppler-derived indexes of the study population. Variables are shown as means \pm S.D.

\begin{tabular}{|c|c|c|c|}
\hline & $\begin{array}{c}\text { Before } \\
\text { adrenalectomy } \\
(n=24)\end{array}$ & $\begin{array}{c}\text { After } \\
\text { adrenalectomy } \\
(n=24)\end{array}$ & P-value \\
\hline IVS (mm) & $10.3 \pm 1.7$ & $9.3 \pm 1.1$ & $<0.005$ \\
\hline LVED (mm) & $47.8 \pm 5.0$ & $48.3 \pm 3.9$ & NS \\
\hline LVES (mm) & $29.7 \pm 3.9$ & $28.9 \pm 4.3$ & NS \\
\hline PWT (mm) & $10.1 \pm 1.5$ & $9.2 \pm 0.8$ & $<0.05$ \\
\hline RWT & $0.43 \pm 0.08$ & $0.39 \pm 0.05$ & $<0.05$ \\
\hline $\mathrm{LA}(\mathrm{mm})$ & $37.6 \pm 5.0$ & $35.2 \pm 3.9$ & $<0.05$ \\
\hline LVMi/BSA $\left(\mathrm{g} / \mathrm{m}^{2}\right)$ & $95.3 \pm 18.7$ & $83.6 \pm 17.8$ & $<0.05$ \\
\hline LVMi $\left(\mathrm{g} / \mathrm{m}^{2.7}\right)$ & $43.2 \pm 10.6$ & $37.9 \pm 9.7$ & $<0.05$ \\
\hline LVEF & $0.66 \pm 0.07$ & $0.65 \pm 0.05$ & NS \\
\hline$E / e^{\prime}$ & $9.0 \pm 2.1$ & $9.4 \pm 2.7$ & NS \\
\hline
\end{tabular}

E/e', pulsed-wave Doppler/tissue Doppler imaging ratio of E and e' wave velocity; IVS, interventricular septum end-diastolic diameter; LA, left atrium; LVED, left ventricle end-diastolic diameter; LVEF, left ventricle ejection fraction; LVES, left ventricle end-systolic diameter; LVMi, left ventricular mass index to the 2.7th power of height in metres; LVMi/BSA, left ventricular mass index to the body surface area; NS, non-significant; PWT, posterior wall thickness end-diastolic diameter; RWT, relative wall thickness. stimulation due to emotional or physical trigger or due to catecholamine excess because of CNS disorders $(32,33)$ or duetoPPGLlikethe diseaseitself (34). This activationleads to myocardial dysfunction by multiple mechanisms. The first presumptive mechanism is myocardial microcirculation dysfunction, which is most likely caused by the effect of catecholamines on $\alpha_{1}$-receptors and subsequently by endothelin on its receptor type A (35). The second probable mechanism leading to myocardial damage is the direct toxic effect of catecholamine on cardiomyocytes. This extreme catecholamine overproduction is characterized by contraction band necrosis, hypercontracted sarcomeres and interstitial mononuclear inflammation in endomyocardial biopsies (36). These histopathological changes in PPGLtriggered TTS are then difficult to distinguish from the changes caused by 'common' TTS $(37,38)$. The myocardial response to catecholamines overproduction is mediated through $\beta_{1^{-}}$and $\beta_{2}$-receptors. The highest density of $\beta$-receptors is more often located in the apical segment of the LV than in other segments and therefore an excess of catecholamine more often affects this region $(17,39)$. Therefore, TTS is morphologically manifested most often by an apical kinetics disorder, called 'apical ballooning', where severe dysfunction of the apical segments of the LV occurs $(40,41)$.

In our group of patients with PHEO before adrenalectomy, a diffuse decrease in LS was observed in all segments of the LV. Twelve patients had the lowest regional LS values in the apical segments of $L V$ and 12 in the basal segments. TTS may not only affect the apical segments but may also appear in other segments or focal points throughout the heart (9). Atypical localization of the kinetics disorder in TTS is relatively rare and varies around 18\% (42). The reverse form of TTS proves to be very rare, at around $1-2.2 \%$, while the occurrence of midventricular forms is more common, around $14.6-17 \%$ (42, 43). Our results are consistent with the analysis of Y-Hassan that confirmed a more frequent occurrence of reverse forms of PPGL-triggered TTS with a prevalence of $30 \%$ vs

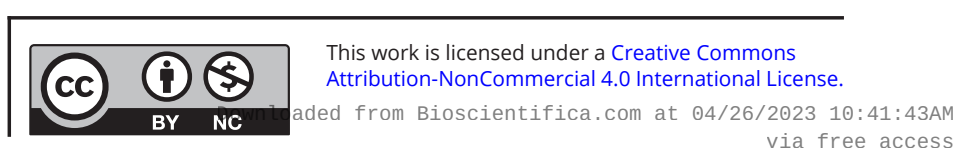


Table 7 Longitudinal strain parameters of the study population. Variables are shown as means \pm S.D.

\begin{tabular}{l}
\hline Global LS (\%) \\
Basal LV LS (\%) \\
Mid-ventricular LV LS (\%) \\
Apical LV LS (\%)
\end{tabular}

\begin{tabular}{c}
\hline Before adrenalectomy $(n=24)$ \\
\hline$-14.3 \pm 1.8$ \\
$-14.6 \pm 2.7$ \\
$-15.6 \pm 1.8$ \\
$-15.3 \pm 3.4$
\end{tabular}

\begin{tabular}{c}
\hline After adrenalectomy $(n=24)$ \\
\hline$-17.7 \pm 1.6$ \\
$-16.2 \pm 2.1$ \\
$-17.5 \pm 2.1$ \\
$-20.7 \pm 3.2$ \\
\hline
\end{tabular}

\section{P-value}

$<0.001$

$<0.05$

$<0.005$

$<0.001$

$E F$, ejection fraction; GLS, global longitudinal strain; LV LS, left ventricle longitudinal strain.

above-mentioned $2.2 \%$ in the unselected population with TTS (34). This study also describes the relatively common occurrence (around 20\%) of the so-called global TTS, which is specific for myocardial dysfunction because of PPGL and which is also consistent with our finding of a more global decline of regional LS in analysed segments before adrenalectomy.

After adrenalectomy, all but one patient had an improvement in GLS. The overall values of the regional LS also improved, with these positive changes being most evident in the apical segments of the LV. A decrease in regional LS was observed in three patients in the midventricular segments and, surprisingly, even in ninepatients in the basal segments of LV. The most significant changes in the apical segments of LV could be related to the abovementioned hypothesis of a higher density of $\beta$-receptors in this area. On the other hand, the minor increase or even partial decrease of regional LS in basal and mid-ventricular segments remains unclear. The explanation could be in the different pathophysiologic influence of catecholamines on

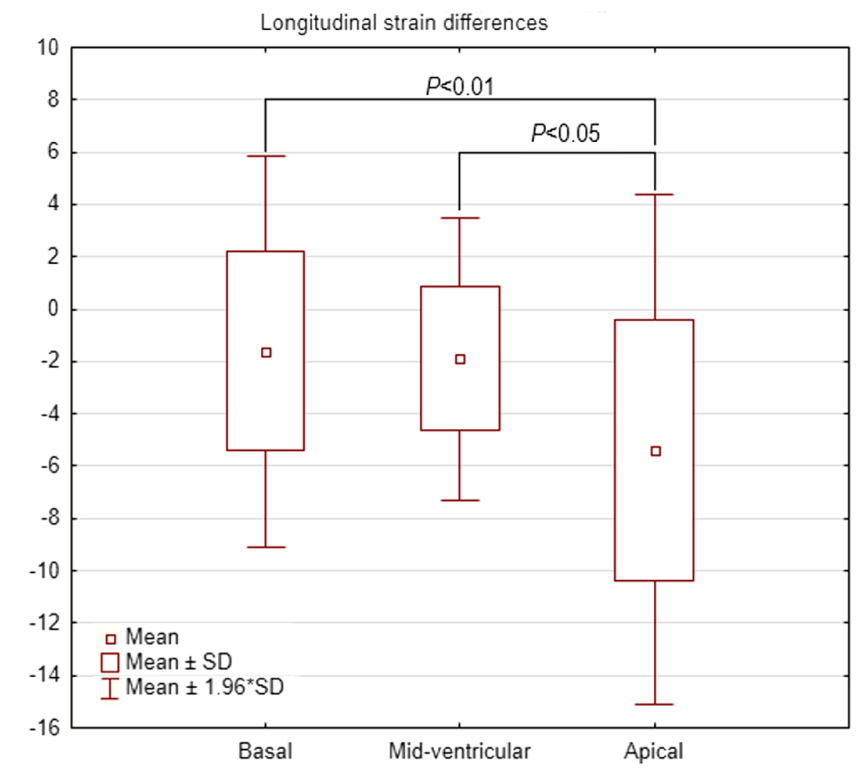

Figure 2

Left ventricle longitudinal strain differences before and after adrenalectomy. individual LV segments. While arterial hypertension leads to a more diffuse decrease in LS in all LV segments (44), an excessive amount of catecholamines can cause myocardial dysfunction by its own cardiotoxic effect and at the same time by the haemodynamic effect leading to increased afterload. Because subsequent upregulation of $\beta$-receptors after removal of an excess of catecholamines is relatively fast (45), changes in the mainly hypertension-damaged tissue may subside more slowly or the pathological effect of concomitant arterial hypertension on LS values may persist even after adrenalectomy. The negative hemodynamic effect of arterial hypertension is evident by a statistically significant reduction in wall dimensions and regression of LV mass in our patients with PHEO after adrenalectomy. Another factor may be the increased variability of blood pressure in patients with PPGL (46) and the absence of a nocturnal decrease (non-dipping) on 24-h blood pressure monitoring or even a reversal increase (reverse dipping), which is associated with a higher incidence of target organ damage (47).

Despite the similar pathophysiological effect of PPGL and TTS on LV function, there are several differences to be aware of. PPGL are more often manifested by a more chronic course, while TTS is more often an acute disease. In addition, PPGL cause other complex metabolic changes, some of which could be related to a smaller increase in regional strain in some segments of the LV. The role of arterial hypertension has been mentioned above. Another pathological phenomenon in patients with PHEO is impaired glucose tolerance up to the development of diabetes (48). It is known that patients with type 2 diabetes have a significant reduction in GLS, which is associated with a worse prognosis (49). Although glucose metabolism improves after adrenalectomy $(50,51)$, it cannot be ruled out that subclinical involvement of LV may persist to some extent. Finally, the decline of GLS is well documented in patients with the systemic inflammatory response syndrome and the magnitude of the decline of GLS is related to the prognosis of these patients (52). In our previous study, we showed that chronic catecholamine excess in subjects with PHEO was accompanied by an 
Table 8 Differences in longitudinal strain among left ventricle segments. Variables are shown as means \pm S.D.

\begin{tabular}{l}
\hline LV segment \\
\hline Before adrenalectomy \\
After adrenalectomy \\
Difference
\end{tabular}

\begin{tabular}{c}
\hline Apical LS $(\%)(n=24)$ \\
\hline$-15.3 \pm 3.4$ \\
$-20.7 \pm 3.2^{\star \star, \# \# \#}$ \\
$-5.4 \pm 5.0^{\star}, \# \#$
\end{tabular}

\begin{tabular}{c}
\hline Mid-ventricular LS $(\%)(n=24)$ \\
\hline$-15.6 \pm 1.8$ \\
$-17.5 \pm 2.1$ \\
$-1.9 \pm 2.7$
\end{tabular}

\begin{tabular}{c} 
Basal LS $(\%)(n=24)$ \\
\hline$-14.6 \pm 2.7$ \\
$-16.2 \pm 2.1$ \\
$-1.6 \pm 3.8$ \\
\hline
\end{tabular}

ANOVA P-value

0.600

$<0.001$

$<0.01$

${ }^{*} P<0.05,{ }^{* *} P<0.01$, vs mid-ventricular; ${ }^{\#} P<0.01,{ }^{\# \# \#} P<0.001$ vs basal.

LS, longitudinal strain; LV, left ventricle.

increase in inflammatory markers, which was reversed by the tumour removal (53), therefore systemic inflammation may also influence our results.

We are aware of the limitations of our study. PHEO is a rare disease, and we are not able to enroll a larger number of patients into the study. Moreover, speckle-tracking analysis requires good quality of echocardiographic records and therefore patients with poor recording quality had to be excluded from the study. The second limitation of our study is the absence of free urinary catecholamine values; therefore, it was not possible to correlate catecholamine levels with various echocardiographic, biochemical and clinical data, which are usually of high significance. In that way, we are not able to evaluate causality between influences of urine catecholamine levels on GLS changes. The third limitation is the insufficient representation of patients with noradrenergic biochemical phenotype. The representation of only six patients with the noradrenergic biochemical phenotype did not allow us to sufficiently evaluate the influence of the biochemical phenotype on regional changes in LS values. These regional changes may be caused by the different affinity of adrenaline and noradrenaline for $\beta_{1}$ - and $\beta_{2}$-receptors since adrenaline has a higher affinity for $\beta_{2}$ - and noradrenaline for the $\beta_{1}$-receptor. Basal segments of the LV have fewer $\beta_{2}$-receptors. As opposed to the apical segments, where the $\beta_{2}$-receptors can be found in abundance. There is a sufficient $\beta_{2}$-receptor stimulation in patients with adrenergic phenotype and there is a 'molecular switch' from the positive inotropic $G_{s}$ to the negatively inotropic $\mathrm{G}_{\mathrm{i}}$ pathway $(41,54)$. This may spare the apical segments from excessive contraction and contraction band necrosis and therefore allow for better recovery of systolic function. On the other hand, basal segments of the LV have more $\beta_{1}$-receptors. Therefore, patients with the noradrenergic phenotype do not have a sufficient $\beta_{2}$-receptor stimulation but an abundance of $\beta 1$-receptor stimulation, so there is a lack of $G_{\mathrm{s}}$ to the $\mathrm{G}_{\mathrm{i}}$ pathway switch. This can lead to excessive contraction, contraction band necrosis and a diminished ability to recover systolic function at the basal segments.

Despite the above limitations, it can be concluded that our study confirmed the positive effect of adrenalectomy on the regression of subclinical LV impairment

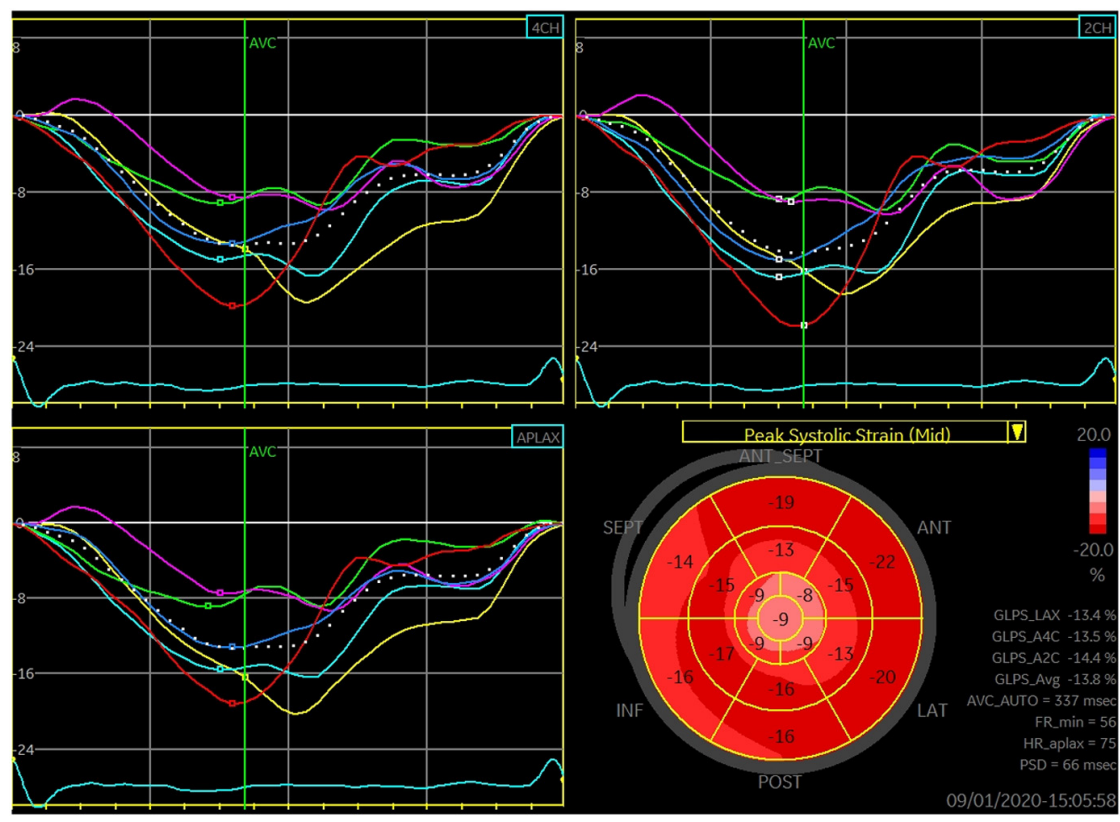

\section{Figure 3}

Global longitudinal strain before adrenalectomy. The green and purple curves represent apical segments. GLPS, global longitudinal peak strain; $4 \mathrm{CH}$, apical four chamber view, $2 \mathrm{CH}$, apical two chamber view; APLAX, apical long-axis view; MID, mid-wall; AVC, aortic valve closure; ANT-SEPT, anterior-septal; ANT, anterior; LAT, lateral; POST, posterior; INF, inferior; SEPT, septal; HR, heart rate. https://ec.bioscientifica.com https://doi.org/10.1530/EC-21-0462 (c) 2021 The authors Published by Bioscientifica Ltd
This work is licensed under a Creative Commons Attribution-NonCommercial 4.0 International License. ded from Bioscientifica.com at 04/26/2023 10:41:43AM 


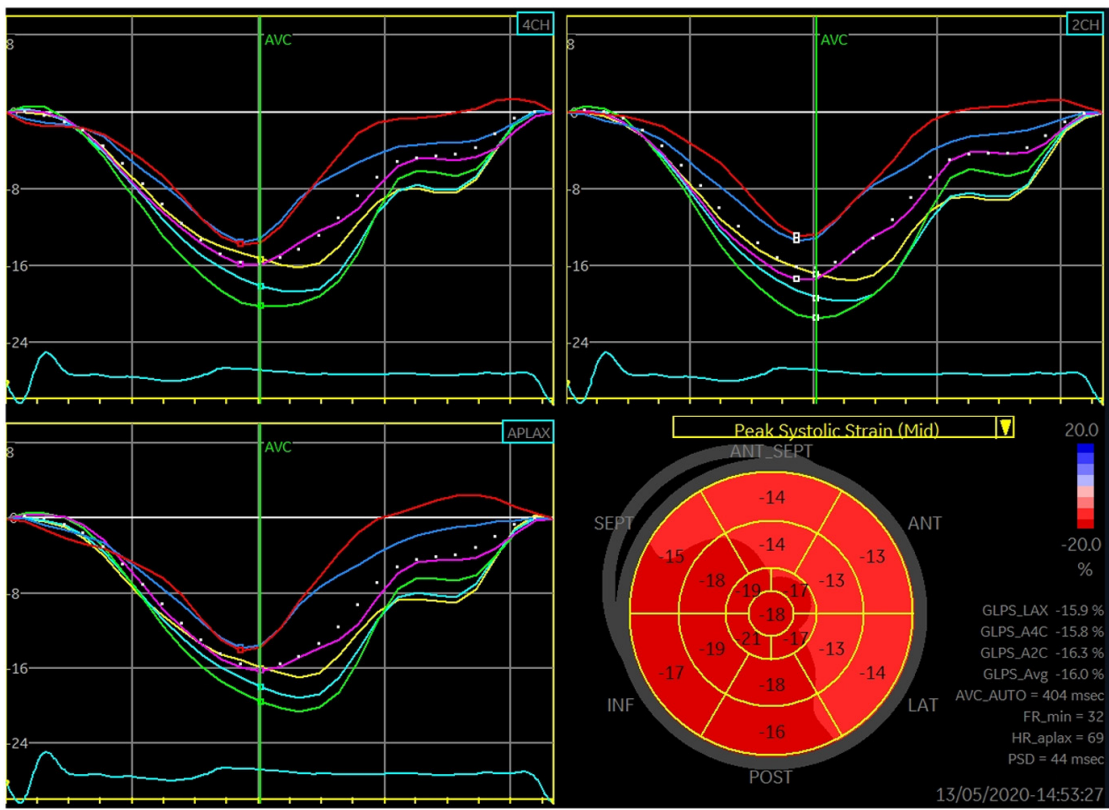

\section{Figure 4}

Global longitudinal strain after adrenalectomy. The green and purple curves represent apical segments. GLPS, global longitudinal peak strain; $4 \mathrm{CH}$, apical four chamber view, $2 \mathrm{CH}$, apical two chamber view; APLAX, apical long-axis view; MID, mid-wall; AVC, aortic valve closure; ANT-SEPT, anterior-septal; ANT, anterior; LAT, lateral; POST, posterior; INF, inferior; SEPT, septal; HR, heart rate.

characterized by improvement of GLS values. The main original finding of our study is that the most pronounced changes in regional LS after adrenalectomy occurred in the apical segments of the LV. The most likely explanation is the higher concentration of specific $\beta$-receptors in this $\mathrm{LV}$ area manifested with the higher direct toxic effect of catecholamines on the myocardium.

\section{Declaration of interest}

The authors declare that there is no conflict of interest that could be perceived as prejudicing the impartiality of the research reported.

\section{Funding}

This study was supported by Research Projects of the Charles University in Prague: Progres Q25 and Q28 and by research grant \#NV19-01-00083 from the Ministry of Health of the Czech Republic; Ministry of Health, Czech Republic - conceptual development of research organization 64165, General University Hospital in Prague, Czech Republic.

\section{Institutional review board statement}

The study was conducted according to the guidelines of the Declaration of Helsinki and approved by the Ethics Committee of General University Hospital and First Faculty of Medicine, Charles University in Prague (on 21 May 2015, code 20/15).

\section{Informed consent statement}

Informed consent was obtained from all subjects involved in the study.

\section{Acknowledgements}

Special thanks go to the nurses Terezie Holajová and Eva Straková from the echocardiography laboratory at the Third Department of Medicine for assistance during the study.

\section{References}

1 Pacak K, Keiser HR \& Eisenhofer G. Pheochromocytoma. In Endocrinology, 5th ed., pp. 2501-2534. Eds LJ DeGroot \& JL Jamenson. Philadelphia: Elsevier Saunders, 2006.

2 Ariton M, Juan CS \& AvRuskin TW. Pheochromocytoma: clinical observations from a Brooklyn Tertiary Hospital. Endocrine Practice 20006 249-252. (https://doi.org/10.4158/EP.6.3.249)

3 Omura M, Saito J, Yamaguchi K, Kakuta Y \& Nishikawa T. Prospective study on the prevalence of secondary hypertension among hypertensive patients visiting a general outpatient clinic in Japan. Hypertension Research 200427 193-202. (https://doi.org/10.1291/ hypres.27.193)

4 Lenders JW, Eisenhofer G, Mannelli M \& Pacak K. Phaeochromocytoma. Lancet 2005366 665-675. (https://doi. org/10.1016/S0140-6736(05)67139-5)

5 Berends AMA, Buitenwerf E, de Krijger RR, Veeger NJGM, van der Horst-Schrivers ANA, Links TP \& Kerstens MN. Incidence of pheochromocytoma and sympathetic paraganglioma in the Netherlands: a nationwide study and systematic review. European Journal of Internal Medicine 201851 68-73. (https://doi.org/10.1016/j. ejim.2018.01.015)

6 Zelinka T, Eisenhofer G \& Pacak K. Pheochromocytoma as a catecholamine producing tumor: implications for clinical practice. Stress 200710 195-203. (https://doi.org/10.1080/10253890701395896)

7 Zelinka T, Petrák O, Turková H, Holaj R, Štrauch B, Kršek M, Brabcová-Vránková AB, Musil Z, Dušková J, Kubinyi J, et al. High incidence of cardiovascular complications in pheochromocytoma. Hormone and Metabolic Research 201244 379-384. (https://doi. org/10.1055/s-0032-1306294)

8 Majtan B, Zelinka T, Rosa J, Petrák O, Krátká Z, Štrauch B, Tuka V, Vránková A, Michalský D, Novák K, et al. Long-term effect of adrenalectomy on cardiovascular remodeling in patients with pheochromocytoma. Journal of Clinical Endocrinology and Metabolism 2017102 1208-1217. (https://doi.org/10.1210/jc.2016-2422)

9 Ghadri JR, Wittstein IS, Prasad A, Sharkey S, Dote K, Akashi YJ, Cammann VL, Crea F, Galiuto L, Desmet W, et al. International expert consensus document on takotsubo syndrome (Part I): clinical characteristics, diagnostic criteria, and pathophysiology. European Heart Journal 201839 2032-2046. (https://doi.org/10.1093/eurheartj/ ehy076)

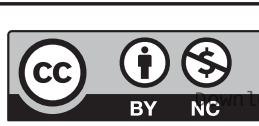

This work is licensed under a Creative Commons Attribution-NonCommercial 4.0 International License. ded from Bioscientifica.com at 04/26/2023 10:41:43AM 
10 Park JH, Kim KS, Sul JY, Shin SK, Kim JH, Lee JH, Choi SW, Jeong JO \& Seong IW. Prevalence and patterns of left ventricular dysfunction in patients with pheochromocytoma. Journal of Cardiovascular Ultrasound 201119 76-82. (https://doi.org/10.4250/jcu.2011.19.2.76)

11 Chiang YL, Chen PC, Lee CC \& Chua SK. Adrenal pheochromocytoma presenting with takotsubo-pattern cardiomyopathy and acute heart failure: a case report and literature review. Medicine 201695 e4846. (https://doi.org/10.1097/MD.0000000000004846)

12 Sun JP, Stewart WJ, Yang XS, Donnell RO, Leon AR, Felner JM, Thomas JD \& Merlino JD. Differentiation of hypertrophic cardiomyopathy and cardiac amyloidosis from other causes of ventricular wall thickening by two-dimensional strain imaging echocardiography. American Journal of Cardiology 2009103 411-415. (https://doi.org/10.1016/j.amjcard.2008.09.102)

13 Lee SH, Park JH, Lee JY, Lee SR, Rhee KS, Chae JK, Kim WH, Sul JY, Oh JK, Kwon HJ, et al. Clinical profiles of patients with surgically resected pheochromocytoma and paraganglioma. Korean Journal of Internal Medicine 201935 351-359. (https://doi.org/10.3904/ kjim.2018.231)

14 Kvasnička J, Zelinka T, Petrák O, Rosa J, Štrauch B, Krátká Z, Indra T, Markvartová A, Widimský J \& Holaj R. Catecholamines induce left ventricular subclinical systolic dysfunction: a speckle-tracking echocardiography study. Cancers 201911 318. (https://doi. org/10.3390/cancers11030318)

15 Dobrowolski P, Januszewicz A, Klisiewicz A, Gosk-Przybylek M, Peczkowska M, Kabat M, Kwapiszewska A, Warchol-Celinska E, Ambroziak U, Doroszko A, et al. Left ventricular structural and functional alterations in patients With pheochromocytoma/ paraganglioma before and after surgery. JACC: Cardiovascular Imaging 202013 2498-2509. (https://doi.org/10.1016/j.jcmg.2020.07.017)

16 Elenkova A, Shabani R, Kinova E, Vasilev V, Goudev A \& Zacharieva S. Global longitudinal strain as a marker for systolic function in patients with pheochromocytomas. Endocrine-Related Cancer 202027 561-570. (https://doi.org/10.1530/ERC-20-0137)

17 Lyon AR, Rees PS, Prasad S, Poole-Wilson PA \& Harding SE. Stress (takotsubo) cardiomyopathy - a novel pathophysiological hypothesis to explain catecholamine-induced acute myocardial stunning. Nature Clinical Practice: Cardiovascular Medicine 20085 22-29. (https://doi. org/10.1038/ncpcardio1066)

18 Tafreshi S, Naqvi SY \& Thomas S. Extra-adrenal pheochromocytoma presenting as inverse takotsubo-pattern cardiomyopathy treated with surgical resection. BMJ Case Reports 201811 e226384. (https://doi. org/10.1136/bcr-2018-226384)

19 Eisenhofer G, Lenders JW, Goldstein DS, Mannelli M, Csako G, Walther MM, Brouwers FM \& Pacak K. Pheochromocytoma catecholamine phenotypes and prediction of tumor size and location by use of plasma free metanephrines. Clinical Chemistry 200551 735-744. (https://doi.org/10.1373/clinchem.2004.045484)

20 Eisenhofer G, Timmers HJ, Lenders JW, Bornstein SR, Tiebel O, Mannelli M, King KS, Vocke CD, Linehan WM, Bratslavsky G, et al. Age at diagnosis of pheochromocytoma differs according to catecholamine phenotype and tumor location. Journal of Clinical Endocrinology and Metabolism 201196 375-384. (https://doi. org/10.1210/jc.2010-1588)

21 Williams B, Mancia G, Spiering W, Agabiti Rosei E, Azizi M, Burnier M, Clement D, Coca A, De Simone G, Dominiczak A, et al. 2018 Practice Guidelines for the management of arterial hypertension of the European Society of Hypertension and the European Society of Cardiology: ESH/ESC Task Force for the management of arterial hypertension. Journal of Hypertension 201836 2284-2309. (https://doi org/10.1097/HJH.0000000000001961)

22 Ramaraj R \& Movahed MR. Reverse or inverted takotsubo cardiomyopathy (reverse left ventricular apical ballooning syndrome) presents at a younger age compared with the mid or apical variant and is always associated with triggering stress. Congestive Heart Failure 2010 16 284-286. (https://doi.org/10.1111/j.1751-7133.2010.00188.x)
23 Mach F, Baigent C, Catapano AL, Koskinas KC, Casula M, Badimon L, Chapman MJ, De Backer GG, Delgado V, Ference BA, et al. 2019 ESC/EAS Guidelines for the management of dyslipidaemias: lipid modification to reduce cardiovascular risk. European Heart Journal 2020 41 111-188. (https://doi.org/10.1093/eurheartj/ehz455)

24 Lenders JW, Eisenhofer G, Armando I, Keiser HR, Goldstein DS \& Kopin IJ. Determination of metanephrines in plasma by liquid chromatography with electrochemical detection. Clinical Chemistry 199339 97-103. (https://doi.org/10.1093/clinchem/39.1.97)

25 Lang RM, Badano LP, Mor-Avi V, Afilalo J, Armstrong A, Ernande L, Flachskampf FA, Foster E, Goldstein SA, Kuznetsova T, et al. Recommendations for cardiac chamber quantification by echocardiography in adults: an update from the American Society of Echocardiography and the European Association of Cardiovascular Imaging. European Heart Journal: Cardiovascular Imaging 201516 233-270. (https://doi.org/10.1093/ehjci/jev014)

26 Mor-Avi V, Lang RM, Badano LP, Belohlavek M, Cardim NM, Derumeaux G, Galderisi M, Marwick T, Nagueh SF, Sengupta PP, et al. Current and evolving echocardiographic techniques for the quantitative evaluation of cardiac mechanics: ASE/EAE consensus statement on methodology and indications endorsed by the Japanese Society of Echocardiography. European Journal of Echocardiography 2011 12 167-205. (https://doi.org/10.1093/ejechocard/jer021)

27 Farsalinos KE, Daraban AM, Unlu S, Thomas JD, Badano LP \& Voigt JU. Head-to-head comparison of global longitudinal strain measurements among nine different vendors: the EACVI/ASE inter-vendor comparison study. Journal of the American Society of Echocardiography 201528 1171-1181, e2. (https://doi.org/10.1016/j.echo.2015.06.011)

28 Cheng S, Larson MG, McCabe EL, Osypiuk E, Lehman BT, Stanchev P, Aragam J, Benjamin EJ, Solomon SD \& Vasan RS. Reproducibility of speckle-tracking-based strain measures of left ventricular function in a community-based study. Journal of the American Society of Echocardiography 201326 1258.e2-1266.e2. (https://doi.org/10.1016/j. echo.2013.07.002)

29 Inoue K, Okayama H, Nishimura K, Nagai T, Suzuki J, Ogimoto A, Saito M, Yoshii T, Hiasa G, Sumimoto T, et al. Impact of septal curvature on regional strain in patients with hypertrophic cardiomyopathy. Circulation Journal 201377 1040-1045. (https://doi. org/10.1253/circj.cj-12-0752)

30 Phelan D, Collier P, Thavendiranathan P, Popovic ZB, Hanna M, Plana JC, Marwick TH \& Thomas JD. Relative apical sparing of longitudinal strain using two-dimensional speckle-tracking echocardiography is both sensitive and specific for the diagnosis of cardiac amyloidosis. Heart 201298 1442-1448. (https://doi. org/10.1136/heartjnl-2012-302353)

31 Kramer J, Niemann M, Liu D, Hu K, Machann W, Beer M, Wanner C, Ertl G \& Weidemann F. Two-dimensional speckle tracking as a noninvasive tool for identification of myocardial fibrosis in Fabry disease. European Heart Journal 201334 1587-1596. (https://doi.org/10.1093/ eurheartj/eht098)

32 Finsterer J \& Wahbi K. CNS disease triggering takotsubo stress cardiomyopathy. International Journal of Cardiology 2014177 322-329. (https://doi.org/10.1016/j.ijcard.2014.08.101)

33 Templin C, Ghadri JR, Diekmann J, Napp LC, Bataiosu DR, Jaguszewski M, Cammann VL, Sarcon A, Geyer V, Neumann CA, et al. Clinical features and outcomes of takotsubo (stress) cardiomyopathy. New England Journal of Medicine 2015373 929-938. (https://doi. org/10.1056/NEJMoa1406761)

34 Y-Hassan S. Clinical features and outcome of pheochromocytomainduced takotsubo syndrome: analysis of 80 published cases. American Journal of Cardiology 2016117 1836-1844. (https://doi.org/10.1016/j. amjcard.2016.03.019)

35 Cohen RA, Shepherd JT \& Vanhoutte PM. Prejunctional and postjunctional actions of endogenous norepinephrine at the sympathetic neuroeffector junction in canine coronary arteries. Circulation Research 198352 16-25. (https://doi.org/10.1161/01.res.52.1.16)

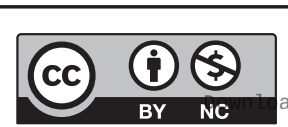

This work is licensed under a Creative Commons Attribution-NonCommercial 4.0 International License. ded from Bioscientifica.com at 04/26/2023 10:41:43AM 
36 Wittstein IS. Stress cardiomyopathy: a syndrome of catecholaminemediated myocardial stunning? Cellular and Molecular Neurobiology 201232 847-857. (https://doi.org/10.1007/s10571-012-9804-8)

37 Frustaci A, Loperfido F, Gentiloni N, Caldarulo M, Morgante E \& Russo MA. Catecholamine-induced cardiomyopathy in multiple endocrine neoplasia. A histologic, ultrastructural, and biochemical study. Chest 199199 382-385. (https://doi.org/10.1378/chest.99.2.382)

38 Samuels MA. The brain-heart connection. Circulation 2007 116 77-84. (https://doi.org/10.1161/CIRCULATIONAHA.106.678995)

39 Mori H, Ishikawa S, Kojima S, Hayashi J, Watanabe Y, Hoffman JI \& Okino H. Increased responsiveness of left ventricular apical myocardium to adrenergic stimuli. Cardiovascular Research 199327 192-198. (https://doi.org/10.1093/cvr/27.2.192)

40 Lyon AR, Bossone E, Schneider B, Sechtem U, Citro R, Underwood SR, Sheppard MN, Figtree GA, Parodi G, Akashi YJ, et al. Current state of knowledge on Takotsubo syndrome: a position statement from the taskforce on Takotsubo Syndrome of the Heart Failure Association of the European Society of Cardiology. European Journal of Heart Failure 201618 8-27. (https://doi.org/10.1002/ejhf.424)

41 Paur H, Wright PT, Sikkel MB, Tranter MH, Mansfield C, O'Gara P, Stuckey DJ, Nikolaev VO, Diakonov I, Pannell L, et al. High levels of circulating epinephrine trigger apical cardiodepression in a beta2adrenergic receptor/Gi-dependent manner: a new model of takotsubo cardiomyopathy. Circulation 2012126 697-706. (https://doi. org/10.1161/CIRCULATIONAHA.112.111591)

42 Eitel I, von Knobelsdorff-Brenkenhoff F, Bernhardt P, Carbone I, Muellerleile K, Aldrovandi A, Francone M, Desch S, Gutberlet M, Strohm O, et al. Clinical characteristics and cardiovascular magnetic resonance findings in stress (takotsubo) cardiomyopathy. JAMA 2011 306 277-286. (https://doi.org/10.1001/jama.2011.992)

43 Ghadri JR, Cammann VL, Napp LC, Jurisic S, Diekmann J, Bataiosu DR, Seifert B, Jaguszewski M, Sarcon A, Neumann CA, et al. Differences in the clinical profile and outcomes of typical and atypical takotsubo syndrome: data from the international takotsubo registry. JAMA Cardiology 20161 335-340. (https://doi.org/10.1001/ jamacardio.2016.0225)

44 Trivedi SJ, Altman M, Stanton T \& Thomas L. Echocardiographic strain in clinical practice. Heart, Lung and Circulation 201928 1320-1330. (https://doi.org/10.1016/j.hlc.2019.03.012)

45 Wang X, Sentex E, Saini HK, Chapman D \& Dhalla NS. Upregulation of beta-adrenergic receptors in heart failure due to volume overload. American Journal of Physiology: Heart and Circulatory Physiology 2005 289 H151-H159. (https://doi.org/10.1152/ajpheart.00066.2005)
46 Zelinka T, Štrauch B, Petrák O, Holaj R, Vránková A, Weisserová H, Pacák K \& Widimský Jr J. Increased blood pressure variability in pheochromocytoma compared to essential hypertension patients. Journal of Hypertension 200523 2033-2039. (https://doi. org/10.1097/01.hjh.0000185714.60788.52)

47 Petrak O, Rosa J, Holaj R, Strauch B, Kratka Z, Kvasnicka J, Klimova J, Waldauf P, Hamplova B, Markvartova A, et al. Blood pressure profile, catecholamine phenotype, and target organ damage in pheochromocytoma/paraganglioma. Journal of Clinical Endocrinology and Metabolism 2019 104 5170-5180. (https://doi.org/10.1210/jc.2018-02644)

48 La Batide-Alanore A, Chatellier G \& Plouin PF. Diabetes as a marker of pheochromocytoma in hypertensive patients. Journal of Hypertension 200321 1703-1707. (https://doi.org/10.1097/00004872-20030900000020)

49 Holland DJ, Marwick TH, Haluska BA, Leano R, Hordern MD, Hare JL, Fang ZY, Prins JB \& Stanton T. Subclinical LV dysfunction and 10-year outcomes in type 2 diabetes mellitus. Heart 2015101 1061-1066. (https://doi.org/10.1136/heartjnl-2014-307391)

50 Komada H, Hirota Y, So A, Nakamura T, Okuno Y, Fukuoka H, Iguchi G, Takahashi Y, Sakaguchi K \& Ogawa W. Insulin secretion and insulin sensitivity before and after surgical treatment of pheochromocytoma or paraganglioma. Journal of Clinical Endocrinology and Metabolism 2017 102 3400-3405. (https://doi.org/10.1210/jc.2017-00357)

51 Wiesner TD, Bluher M, Windgassen M \& Paschke R. Improvement of insulin sensitivity after adrenalectomy in patients with pheochromocytoma. Journal of Clinical Endocrinology and Metabolism 200388 3632-3636. (https://doi.org/10.1210/jc.2003-030000)

52 Sanfilippo F, Corredor C, Fletcher N, Tritapepe L, Lorini FL, Arcadipane A, Vieillard-Baron A \& Cecconi M. Left ventricular systolic function evaluated by strain echocardiography and relationship with mortality in patients with severe sepsis or septic shock: a systematic review and meta-analysis. Critical Care 201822 183. (https://doi. org/10.1186/s13054-018-2113-y)

53 Zelinka T, Petrák O, Štrauch B, Holaj R, Kvasnička J, Mazoch J, Pacák K \& Widimský Jr J. Elevated inflammation markers in pheochromocytoma compared to other forms of hypertension. Neuroimmunomodulation 2007 14 57-64. (https://doi. org/10.1159/000107289)

54 Heubach JF, Ravens U \& Kaumann AJ. Epinephrine activates both Gs and Gi pathways, but norepinephrine activates only the Gs pathway through human beta2-adrenoceptors overexpressed in mouse heart. Molecular Pharmacology 200465 1313-1322. (https://doi.org/10.1124/ mol.65.5.1313)

Received in final form 14 October 2021

Accepted 3 November 2021

Accepted Manuscript published online 4 November 2021 https://ec.bioscientifica.com

https://doi.org/10.1530/EC-21-0462 (c) 2021 The authors Published by Bioscientifica Ltd

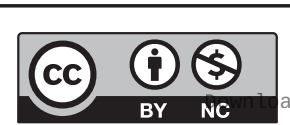

This work is licensed under a Creative Commons Attribution-NonCommercial 4.0 International License. ded from Bioscientifica.com at 04/26/2023 10:41:43AM 